\title{
Paragenesis mechanism of anthraxolite and vanadium: A case study of the Tanjianshan Group in the Northern Margin of the Qaidam Basin
}

\author{
Chenglin Liu ${ }^{1,2 *}$, Chao Dun ${ }^{1,2}$, Yuanyuan Yang ${ }^{3}$, Xiaohu Wang ${ }^{3}$, Chao Tong ${ }^{1,2}$, Zhihui Zhang ${ }^{1,2}$, Mengxue Chen and Yu Li ${ }^{1,2}$ \\ ${ }^{\prime}$ College of Geoscience, China University of Petroleum, Beijing, 102249, China \\ ${ }^{2}$ State Key Laboratory of Petroleum Resource and Prospecting, China University of Petroleum, Beijing, 102249, China \\ ${ }^{3}$ Institute of Geomechanics, Chinese Academy of Geological Sciences, Beijing, 100081, China
}

\section{Article Info}

\section{*Corresponding author:}

Chenglin Liu

College of Geoscience

China University of Petroleum

Beijing, 102249, China

E-mail: liucl@cup.edu.cn

Received: March 15, 2017

Accepted: April 13, 2017

Published: April 18, 2017

Citation: Liu C, Dun C, Yang Y, et al. Paragenesis mechanism of anthraxolite and vanadium: A case study of the Tanjianshan Group in the Northern Margin of the Qaidam Basin. Int J Petrochem Res. 2017; 1(1): 46-49. doi: 10.18689/ijpr-1000109

Copyright: () 2017 The Author(s). This work is licensed under a Creative Commons Attribution 4.0 International License, which permits unrestricted use, distribution, and reproduction in any medium, provided the original work is properly cited.

Published by Madridge Publishers

\begin{abstract}
The enrichment of metallic elements in organic matter or oil and gas is a common phenomenon, but how vanadium is concentrated in anthraxolite and the interaction mechanism between organic matter and vanadium are not clear. The anthraxolite in the Tanjianshan Group in the Northern Margin of the Qaidam Basin generally contains a relatively high amount of vanadium. In order to discuss the origin of the anthraxolite and why the anthraxolite is rich in vanadium, we conducted research on organic geochemical analysis and petrochemistry. The results show that the extent of anthraxolite evolution is extremely high, and the organic matter originated from plankton and was formed in oxygen-poor and salt water. The relative contents and correlation ratios of major and trace elements in sediments indicate that the enrichment of vanadium minerals is almost irrelevant to marine hot water deposition. It is inferred that the initial deposition of vanadium may be mainly associated with biological and biochemical processes, then the element migration and accumulation with hydrocarbon formation and evolution, finally precipitation in anthraxolite.
\end{abstract}

Keywords: Anthraxolite; vanadium; organic matter; biogeochemical mineralization process; Tanjianshan group; the Northern Margin of Qaidam basin

\section{Introduction}

Researchers have been discovering the origin relationship between organic matter and metal elements for a long time [1] [2] [3] [4] [5] [6] [7] [8] [9]. During our geological survey in the Northern Margin of the Qaidam Basin, we have found that the anthraxolite in the Upper Ordovician Tanjianshan Group contains more vanadium than that in the crust, making us think it over: what role does vanadium play and how does it enrich in the process of petroleum generation from hydrocarbon source rocks, and the evolution of light oil to heavy oil, asphalt, and anthraxolite, a highly thermal evolution product of organic matter.

Geologists have a deep understanding of the phenomenon of metal enrichment in butimen, heavy oil and oil sands [10] [11] [12]. The relevant deposits in the black rocks such as vanadium, nickel and molybdenum occurrences are also getting valued by researchers [13] [14] [15]. So, the studies of the relationship between organic matter and metal minerals have become particularly important. At present, although it has been 
recognized that metal ions and their oxides may have important effects in the hydrocarbon generation process, and it has been put forward that clay minerals, transition metal elements and their sulphides, uranium have positive catalytic effects on oil and gas generation [16] [17]. Different metal elements and organic matter at different evolution stages always have different physical and chemical properties, and there is little research on vanadium in anthraxolite currently. Furthermore, studies on fossil energy resources and metal deposits are often carried out independently in sedimentary basins, and the corresponding research methods are quite different. Organic chemical methods are usually used to study oil and gas resources, and the petrochemical methods are generally applied to study metal deposits. In this paper, these measures are combined to discuss the enrichment of vanadium in the anthraxolite, which is rare in previous studies. In this project, the anthraxolite in the Upper Ordovician Tanjianshan Group in the Northern Margin of the Qaidam Basin is being taken as the analysis object. The aim is to explore the origin of the anthraxolite and explain how vanadium is concentrated in anthraxolite. The relevant achievements will be meaningful not only to petroleum and metal ore origin theory, but also to their exploration in the Qaidam basin and others with similar geological background.

\section{Experiments}

To make sure the formation mechanism of anthraxolite and establish the enrichment pattern of vanadium, this study carried out organic geochemistry and petrochemistry tests on the samples from the Tanjianshan Group. Specifically, these tests include extraction of organic matter (EOM), gas chromatography-mass spectrometry (GC-MS) analyses of the saturate fractions, vitrinite reflectance of source rock (Ro), major and trace elements analysis.

EOM was extracted using the Soxhlet extraction method. Rock samples were crushed into 100 mesh grain size and the powdered samples were extracted with chloroform in a Soxhlet extractor and kept in water bath $\left(80^{\circ} \mathrm{C}\right)$ for $48 \mathrm{~h}$. EOM was then obtained after rotary evaporation.

The gas chromatography-mass spectrometry (GC-MS) analyses of the saturate fractions were performed using a Thermo-Finnigan Trace-DSQ instrument. The gas chromatography $(\mathrm{GC})$ oven temperature was initially held at $50^{\circ} \mathrm{C}$ for $1 \mathrm{~min}$, programmed to $120^{\circ} \mathrm{C}$ at $20^{\circ} \mathrm{C} / \mathrm{min}$ and to $250^{\circ} \mathrm{C}$ at $4{ }^{\circ} \mathrm{C} / \mathrm{min}$ and to $310^{\circ} \mathrm{C}$ at $3^{\circ} \mathrm{C} / \mathrm{min}$ and held at $310^{\circ} \mathrm{C}$ for $30 \mathrm{~min}$. Helium was used as carrier gas.

Ro was tested using the MPV-SP microphotometer. Shales were made into optical slices. The objects for measurement were required to be amorphous homogeneous and matrix vitrinites in the slices. The minimum number of measurement points was 30 , and these points were evenly distributed in the slices.

The major and trace elements of the sedimentary rocks were analyzed mainly using a plasma spectrometer. Except for $\mathrm{FeO}$, all other major and trace elements were analyzed by inductively coupled plasma mass spectrometry (ICP-MS). Hydrofluoric acid and sulfuric acid were used to decompose the sample, then the content of $\mathrm{FeO}$ was calculated by the dichromate method.

\section{Results and discussion}

\section{Geochemical characteristics of anthraxolite}

The anthraxolite in the Upper Ordovician Tanjianshan Group has the following geochemical characteristics: (1) the contents of soluble organic matter are low, and the nonhydrocarbon and asphaltene are dominant in the group components; (2) the equivalent vitrinite reflectance of $3.74 \%$ $4.72 \%$, indicating that it is at the stage of over-maturity; (3) Among the regular steranes, the content of $C_{27}$ is higher than that of $\mathrm{C}_{28}$ and $\mathrm{C}_{29^{i}}$ (4) The ratio of $\mathrm{Pr} / \mathrm{Ph}$ in paraffins is between 0.5 and 0.8 , displaying a significant phytane dominance; (5) The gammacerane index $(\mathrm{G} / \mathrm{C} 3 \mathrm{OH})$ of tricyclic terpanes is generally between 0.18 and 0.27 . These features reveal that the organic matter originated from plankton and formed in oxygen-poor and saline water. The contents and features of hopanes, steranes, triarylstanes and tricyclic terpanes of anthraxolite are similar to that of the mudstone from the Tanjianshan Group, different from other source rocks in the study area, manifesting that the anthraxolite sourced from the mudstone from the Tanjianshan Group [18] [19].

\section{Major and trace elements}

The relative contents and correlation ratios of major and trace elements can reveal the formation environment of sedimentary rocks [20] [21].The ratio of $n\left(\mathrm{SiO}_{2}\right) / \mathrm{n}\left(\mathrm{Al}_{2} \mathrm{O}_{3}\right)$ of the mudstone and limestone rich in anthraxolite is 3.05 to 4.49 with an average value of 3.67 ; the ratio of $n(\mathrm{Al}) / \mathrm{n}(\mathrm{Al}+\mathrm{Fe}+\mathrm{Mn})$ is 0.52 to 0.79 with an average value of 0.61 .The results indicate that the enrichment of vanadium minerals is almost irrelevant to marine hot water deposition. The organic matter originated from plankton, so it is inferred that the initial deposition of vanadium was mainly associated with biological and biochemical processes of the sedimentary environments, and then the element migrated and accumulated with hydrocarbon formation, finally precipitation in anthraxolite.

\section{Discussion about the enrichment mechanism of vanadium}

\section{The initial the enrichment of vanadium}

The analysis of the major and trace elements in rocks has approved that the sedimentary rocks in Tanjianshan Group is mainly from land, with little involvement of hot water deposition, thus proved that the vanadium is not related to hydrothermal sedimentation. Organic geochemical analysis indicates that the anthraxolite from the Tanjianshan Group originated from the marine algae plankton and was formed in the brackish water environment. Some planktons, such as tunicate, brown algae, have positive effects on the enrichment of vanadium [22]. Nitrogen, phosphorus and potassium and metal elements such as vanadium, nickel were brought to the surface water by rivers and rising ocean currents. Vanadium might be captured along with nitrogen, phosphorus and 
potassium taken in into planktons' bodies as nutrition, then it became vanadium porphyrin, which could be well preserved in the suboxic environment after planktons' death. The clay minerals in the seawater also adsorbed vanadium during the deposition process and replace part of the $\mathrm{Al}^{3+}$ into the clay mineral lattice alongside the transfer of the clay minerals' structure in the diagenetic process [13] [23]. It is therefore speculated that the initial enrichment of vanadium in the mudstone of the Tanjianshan Group is mainly related to the adsorption of organism and clay minerals.(fig1.a)

\section{The effects of liquid products generated by organic matter}

The black mudstone from the Tanjianshan Group entered into the oil generation window in the Middle Devonian-Late Devonian [18] [19]. Meanwhile oil and gas migrated into the overlying sandstone and limestone reservoirs. The organic matter released a series of organic functional groups and compounds in the process of decay and thermal degradation, and metal elements escaped from the kerogen as organic complexes. In the process of hydrocarbon generation, organic matter also released humic acid and organic acid. On one hand, these liquid products got vanadium in clay minerals and organic matter activated, dissolved and extracted by changing the $\mathrm{PH}$, solubility and solution polarity in pore water of the source rock. On the other hand, they served as a material transport carrier, vanadium in the form of metal complex migrated along the gradient of the fluid potential from the source rock layer to the reservoirs through open faults and cracks.(fig1.b).

\section{The effects of tectonic movements}

During the period of geological history, the Tanjianshan Group was in the tectonic setting of an active continental margin. After the deposition of the Tanjianshan group, the Northern Margin of the Qaidam Basin had experienced several tectonic movements [18] [19]. Complex tectonic stress field allowed many faults, fractures formed in the terrane, and hydrocarbon fluids were able to migrate and accumulate along these channels. At the end of Late Devonian, after the first large-scale migration of oil and gas generated by the hydrocarbon source rocks in the Tanjianshan Group, there had been several magmatic intrusion in this area. Hydrocarbon fluid baked under the high temperature from the magma cracked, deteriorated, and ultimately evolved intoanthraxolite. At the same time, the baking of high temperature magma provided favorable conditions for the removal of vanadium from hydrocarbon fluids. Generally, the organic matter will be decomposed between $150^{\circ} \mathrm{C}$ and $200^{\circ} \mathrm{C}$ [24]. The high temperature caused by magma broke the complexing balance between organic matter and metal elements, the minerals transported by the organic matter were precipitated due to the decomposition of organic ligands and the lack of inorganic ligands. The destruction of the metal complex structure resulted in the release of vanadium element, and eventually it get enriched in the solid butimen. (fig1.c).

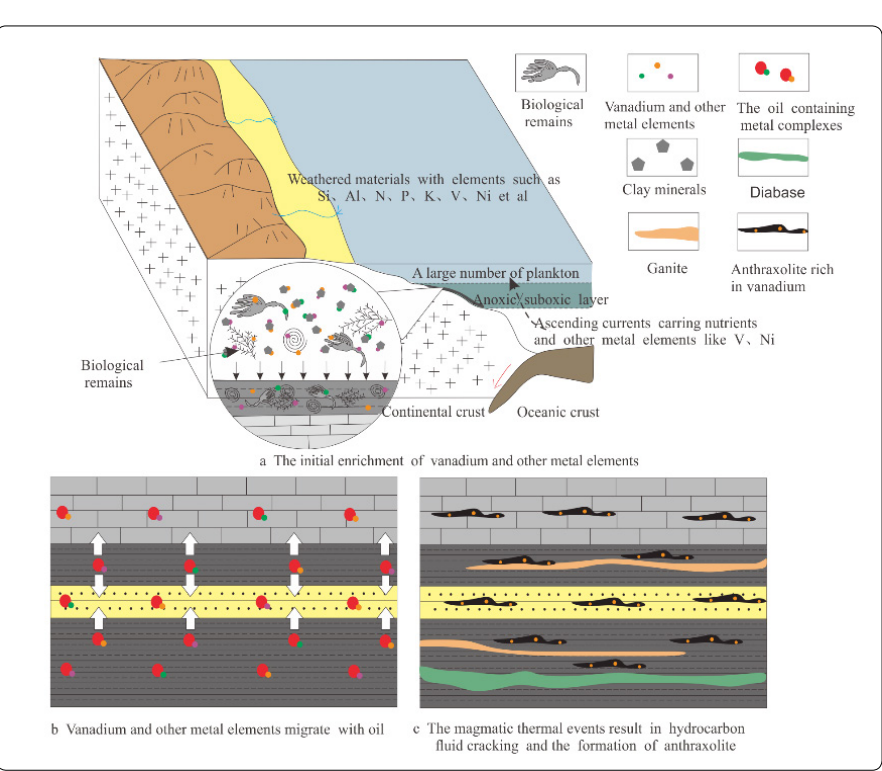

Fig 1. The enrichment pattern of vanadium in the anthraxolite from Tanjianshan Group

\section{Conclusion}

The anthraxolite in the Upper Ordovician Tanjianshan Group was formed by the pyrolysis and metamorphism of the hydrocarbons generated from the black mudstone of the Tanjianshan Group in the Northern Margin of the Qaidam Basin. The petrochemistry analysis shows that the sedimentary rocks of Tanjianshan Group were mainly composed of terrigenous detritus and were not affected by hydrothermal activities. In combination with the organic matter source of anthraxolite, the enrichment of vanadium was related to biological and biochemical processes of the sedimentary environments, and the element migration and accumulation during the hydrocarbon formation and evolution.

\section{Acknowledgement}

This work was supported by the National Natural Science Foundation of China (Grant No. 41572099)

\section{References}

1. Anderson GM. Organic Maturation and Ore Precipitation in Southeast Missouri. Economic Geology.1991; 86: 909-926. doi: 10.2113/ gsecongeo.86.5.909

2. Spirakis CS, Heyl AV. Organic Matter (Bitumen and Other Forms) as the Key to Localisation of Mississippi Valley-Type Ores//Parnell J, Landais P. Bitumen in Ore Deposits. Berlin: Springer-Verlag. 1993: 381-98.

3. Zhou S, Zou H, Xie Q, Jia X. Organic-inorganic interactions during the formation of oils in sedimentary basin. Natural Gas Geoscience. 2006: 17: 42-47.

4. Chen G, Xu G, Wang T, Ma L, Shi L, Zheng C. The relationship between hydrocarbon accumulation and metallization and a discussion on intergrated exploration. Earth Science Frontiers. 2008; 15: 200-06.

5. Gu X, Zhang Y, Li B, Xue C, Dong S, Fu S, Cheng W, Liu L, Wu C. The coupling relationship between metallization and hydrocarbon accumulation in sedimentary basins. Earth Science Frontiers. 2010; 17: 83-105.

6. Li W, Li B, Gu X, Huang Z, Xiao D, Cheng W, Chen C, Dong S. Fluid inclusion evidences for the mineralization of the organic fluid in the Yanwuping mercury deposit, Guizhou. Earth Science Frontiers. 2013; 20: 72-81. 
7. Fang W, Jia R, Guo Y, Li T, Wang L, Huang ZY. Hydrocarbon-rich basin fluid with reductibility and metallogenic mechanism for glutenite-type $\mathrm{Cu}-\mathrm{Pb}-\mathrm{Zn}-\mathrm{U}$ deposits in the western of Tarim Basin. Journal of Earth Sciences and Environment. 2016; 38: 727-52.

8. Sun Y. Organic geochemical zonation characteristics of sandstone-type uranium deposit and its relation to metallization -A case study of Zaohuohao uranium deposit in Inner Mongolia. Uranium Geology. 2016; 32: $129-36$.

9. Yi F, Yi H. Geochemical characteristics of the Beisi Formation manganesebearing rocks of the Lower Triassic Series in the Tiandeng area, Southwest Guangxi and their implications. Geochimica. 2017; 46: 46-65.

10. Songhun $Y$, Sharad DB, Wonkyu L, Heung $Y L$, Soon $Y$ J, Jin-Ook B, Chul WL. Separation and characterization of bitumen from Athabasca oil sand. Korean J. Chem. Eng. 2009; 26(1): 64-71. doi: 10.1007/s11814-0090011-3

11. Yao G. Current status and development prospects for processing of Venezuelan extra-heavy crude and Canadian oil sand bitumen. SinoGlobal Energy. 2012; 17: 3-22.

12. Liliana L, Salvador Lo MA, John KV. Evidence for mixed and biodegraded crude oils in the Socororo field, Eastern Venezuela Basin. Organic Geochemistry. 2015; 82: 12-21. Doi: 10.1016/j.orggeochem.2015.02.006

13. Chen M, Hu Xiang Z, Lu B, Xu Jun W, Bao Z, Bao J. Metallogenic characteristics and genesis of the Yantouzhai vanadium deposit in the northwestern Hunan. Mineral Exploration. 2014; 5: 751-61.

14. Shi C, Cao J, Hu, Han Shanchu, Bian L, Yao S. A review on origin of ni-mo polymetallic deposits in lower Cambrian black rock series in south China. Geological Review. 2011; 57: 719-31.
15. Shu D, Hou B, Zhang M, Xie X. Geochemistry and genesis of vanadium deposits in northeastern Guizhou. Mineral Deposits. 2014; 33: 857-69.

16. Ning Z, Wang W, Wen M, Li J. Catalytic effects of transitional metals on the generation of hydrocarbon in organic matter. Natural Gas Geoscience. 2004; 15(3): 317-19. doi: 10.11764/j.issn.1672-1926.2004.03.317

17. Li S, Lin S, Guo S, Liu L. Effects of inorganic salts on the hydrocarbon generation from kerogens. Geochimica. 2002; 31: 15-20.

18. Liu C, Xu Y, Ma Y, Kang Y, Li Z, Zhang Q, Liu Wg, Cheng H, Yang Y, Dai K, Zheng $C$. Geochemical characteristics and origin of anthraxolite of Tanjianshan group in the northern of Qaidam Basin. Journal of Earth and Environment. 2015; 37: 85-93.

19. Zhang X, Liu C, Xu Y, Ma Y, Yang Y, Li Z, Zhang Q, Liu W, Cao J, Peng B. The anthraxolite generation and metal mineralization in the active continental tectonic edge: A case study of Tanjianshan group in Tanjianshan area in northern margin of the Qaidam Basin. Earth Science Frontiers. 2016; 23: 146-57. doi: 10.13745/j.esf.2016.05.016

20. Jewell PW, Stallard RF. Geochemistry and paleoceanographic setting of central Nevada bedded barites. Journal of Geology. 1991; 99: 151-70.

21. Taylor SR, McLennan SM. The continental crust: Its composition and evolution. Oxford: Blackwell scientific publication. 1985.

22. You X. Research on the Ni-Mo-V deposits in Lower Cambrian black rock series in Western Hunan. 2010.

23. Hu N, Xia H, Dai T, You X, Bao Z, Bao J. Sedimentary vanadium deposit of lower Cambrian black rock series in western Hunan. Contributions to Geology and Mineral Resources Research. 2010; 25: 296-02.

24. Zhuan $\mathrm{H}$, Lu J. Ore deposits connected genetically with organic matter. GeologyGeochemistry. 1996; 6-11. 